\title{
Phylogenetic relationship and genetic differentiation of Populus caspica and Populus alba using cpDNA and ITS noncoding sequences
}

\author{
Hamed Yousefzadeh ${ }^{1}$ - Abasalt Hosseinzadeh Colagar $^{2} \cdot$ Effat Yousefi $^{2} \cdot$ \\ Maryam Badbar ${ }^{2} \cdot$ Gregor Kozlowski $^{3}$
}

Received: 8 October 2016/Accepted: 18 September 2017/Published online: 18 September 2018

(c) Northeast Forestry University and Springer-Verlag GmbH Germany, part of Springer Nature 2018

\begin{abstract}
Populus caspica Bornm. (section Leuce and subsection Albida), one of the most endangered endemic tree species in the Hyrcanian Forest in Iran, has numerous morphological characteristics that are closely similar to Populus alba; to clarify their taxonomic relatedness and genetic differentiation and thus inform conservation strategies, we used the noncoding regions of chloroplast DNA (cpDNA; trnL-F and $t r n H-p s b A$ ) and the internal transcribed spacer (ITS). Leaf samples were collected from six populations across northern Iran. cpDNA and ITS fragments were amplified by universal primers using the PCR technique and directed sequencing. The results showed that $P$. caspica is genetically differentiated from $P$. $a l b a$, and two ITS variants were detected within some $P$.
\end{abstract}

Project funding: This project is supported by grant funding from the Tarbiat Modares University and Mazandaran University.

The online version is available at http://www.springerlink.com

Corresponding editor: Hu Yanbo.

Electronic supplementary material The online version of this article (https://doi.org/10.1007/s11676-018-0785-4) contains supplementary material, which is available to authorized users.

Hamed Yousefzadeh

h.yousefzadeh@modares.ac.ir

$\square$ Abasalt Hosseinzadeh Colagar ahcolagar@umz.ac.ir

1 Department of Environmental Science, Faculty of Natural Resources, Tarbiat Modares University, Tehran, Iran

2 Department of Molecular and Cell Biology, Faculty of Basic Science, University of Mazandaran, Babolsar, Iran

3 Department of Biology and Botanic Garden, University of Fribourg, Fribourg, Switzerland caspica individuals. Conflicts between topologies from ITS and plastid genomes were observed. High differentiation of P. caspica from the other Populus species shown in this study confirmed the diverging taxonomic status of this endangered species. We recommend in situ conservation measures (e.g., protected areas) for at least several populations of this species, especially in the plain regions of the Hyrcanian forest.

Keywords Endangered endemic species - DNA barcoding $\cdot$ Hyrcanian forest $\cdot$ Taxonomic status

\section{Introduction}

Very important forest trees such as aspens, cottonwoods, and poplars, belong in the genus Populus (Salicaceae), commonly called poplars, they are mainly distributed in northern subtropical forests and play a significant ecological role as an indicator species in these regions (Dickmann et al. 2001; Hamzeh and Dayanandan 2004). They are long-lived trees characterized by a dioecious breeding system and wind dispersal of pollen and seeds, and are also commonly used as the model species for tree genomics (Tuskan et al. 2006).

The Hyrcanian forest in northern Iran is located between the Caspian Sea and the Alborz Mountains. These forests comprise $15 \%$ of the Iranian forests and represent $1.1 \%$ of the country's land area (Yousefzadeh et al. 2012). This region has a unique rich biodiversity and is home to many endemic species. Although recognized as a refuge for many Arco-Tertiary relict plants, many forest habitats, and especially the riverine vegetation in the Caspian forest, have been greatly degraded by human activities (Leestmans 2005; Akhani et al. 2010). 
Populus caspica Bornm., one of the most-endangered relict tree species of the Hyrcanian forest (Fallah et al. 2012), is a fast-growing hygrophytic tree, distributed throughout the Hyrcanian forest from the plains to $1400 \mathrm{~m}$ above sea level. Unfortunately, many of these habitats have been destroyed because of land-use changes, illegal exploitation and habitat fragmentation (Colagar et al. 2013). Large-scale interspecific hybridization and high levels of morphological variation among poplars have resulted in great difficulty in the classification of species in systematic and comparative evolutionary research.

Populus caspica has very similar morphological features with $P$. alba and is differentiated mainly by the inflorescence and petiole sizes; the petiole of $P$. caspica is $10-15 \mathrm{~cm}$ long $(P$. alba $10 \mathrm{~cm}$ ) and inflorescence is $20 \mathrm{~cm}$ long $(P$. alba $10-15 \mathrm{~cm})$. Populus alba has many ridges in its bark and grows in the sun, tolerates almost any soils, wet or dry, and is distributed in the river areas of southern Europe, north Africa and central Asia; this species can be found in active floodplains (Hamzeh and Dayanandan 2004). Populus caspica, with few ridges in its bark (Rechinger 1982), is distributed exclusively in the Hyrcanian Forest with other relict tree species, such as Alnus glutinosa, Pterocarya fraxinifolia, and Quercus castaneifolia. Because of the many morphological similarities between these two species, the taxonomic status of $P$. caspica is disputed. In fact, some botanists argue that $P$. caspica and $P$. alba belong to the same species (Rechinger 1982). When morphological similarities prevent accurate plant identification (Brinegar 2009), several molecular markers have been applied to differentiate the species (Khasa et al. 2003; Cervera et al. 2004; Wan et al. 2013).

The trnL-trnF (GAA) in the chloroplast genome is suitable for accurate identification of species at the intraspecific level (Kojoma et al. 2002; Yi et al. 2004; Holt et al. 2004). The length of these regions is another advantage as they are usually shorter than $700 \mathrm{bp}$ (based upon most species examined to date) and can thus be directly amplified and sequenced (Tsai et al. 2006).

The trnH-psbA intergenic spacer is another sequence candidate for resolving lower level relationships (Nitta and O'Grady 2008; Akbarzadeh Roshan et al. 2013). These two regions can be amplified by universal primers (Taberlet et al. 1991; Pirie et al. 2007); hence, they have been the most widely used for phylogenetic studies in plants (Quandt et al. 2004). Conflicts between topologies have often been discovered from different plastid and nuclear genomes. The internal transcribed spacer (ITS) genomes have been interpreted in different ways, such as lineage sorting or reticulation (Wendel and Doyle 1998). ITS regions of nuclear ribosomal DNA have been frequently used for phylogenetic analysis of plants at lower taxonomic levels because of their universality, easy amplification, biparental inheritance and intragenomic uniformity
(Fukuda et al. 2011; Yousefzadeh et al. 2012; Tang et al. 2015). Therefore, we used the ITS regions of nuclear ribosomal DNA to trace potential hybridizations events within a population of $P$. caspica by comparing bootstrap support for lineages resolved by independent topologies and combined trees.

The main objectives of this study were (1) to differentiate the two closely related species $P$. caspica and $P$. alba (section Leuce) and (2) to place P. caspica preliminarily within the genus Populus using sequence data from the plastid and nuclear genome.

\section{Materials and methods}

\section{Plant material, DNA extraction, PCR and sequencing}

Leaves were collected from six small populations of $P$. caspica along an east to west gradient of the Hyrcanian Forest, northern Iran (Appendix 1 in Electronic Supplementary Material), stored on ice and then brought to the lab and frozen in liquid nitrogen and milled to a fine powder. Total DNA was extracted from the ground powder using a combination of the cetyltrimethylammonium bromide (CTAB) and SDS-potassium acetate (Colagar et al. 2010). Before PCR, the DNA extract was electrophoresed in $1 \%$ agarose. The cpDNA noncoding regions trnL-F and $t r n H-$ $p s b A$ intergenic spacer (IGS) were amplified by PCR using the conditions described by Yousefzadeh et al. (2014) and specific primers UEUFF (5'-GGTTCAAGTCCCTCTATC CC- $\left.3^{\prime}\right)$ as the direct primer and UEUFR (5'ATTTGAA CTGGTGACACGAG- $3^{\prime}$ ) as the reverse primer.

The $t r n H-p s b A$ region was amplified with forward primer trnH-GUG (5'-CGCGCATGGTGGATTCACAATCC$\left.3^{\prime}\right)$ and reverse primer $p s b \mathrm{~A}\left(5^{\prime}\right.$-GTTATGCATGAACGTAATGCTC- $\left.3^{\prime}\right)$. The ITS region was amplified using ITS1 (5'-TCCGTAGGTGAACCTGCGG-3') as the direct primer and ITS4 (5'-TCCTCCGCTTATTGATATGC-3') as the reverse primer, which was designed by Taberlet et al. (1991) as a universal primer; the PCR conditions that were used were described by Yousefzadeh et al. (2012).

PCR products were separated by electrophoresis in $1 \%$ agarose. The Taq-PCR products were direct-sequenced by MWG DNA sequencing services (MWG Co., Ebersberg, Germany). The gel electrophoresis and staining were performed by Green and Sambrook (2012) methods.

\section{Phylogenetic analysis}

Electropherograms of the $\operatorname{trn} L-F$ sequences were further checked by eye using the Chromas software program version 2.33. The boundaries of sequences were determined 
via comparison with samples of Populus in searches by Hamzeh and Dayanandan (2004) for $\operatorname{trn} L-F$ and NCBI sequence data for $t r n H-p s b A$ and ITS. Multiple sequence alignment was performed using ClustalW2 in MEGA 6 (Tamura et al. 2013).

The genetic distances among the species were calculated according to Nei (1987), and phylogenetic inferences were made via maximum parsimony (MP). Bootstrap analysis with a fast heuristic search based on 1000 replicates was performed to assess the robustness of the branches. The cutoff value of the consensus tree was $50 \%$, with nodes with bootstrap values of $50 \%$ considered well supported. Additionally, the phylogenetic trees were rooted using Salix species as outgroups.

The phylogenetic network was constructed using the median-joining algorithm with the set of SNPs identified in the ITS and trnH-psbA intergenic spacer. For the medianjoining (MJ) network analysis, all variable characters of the complete alignment were entered into the program package PopART (Leigh and Bryant 2014; software available at: http://popart.otago.ac.nz).

\section{Results}

\section{Characteristics of trnL-F, trnH-psbA and ITS}

A summary of characteristics from the data matrix used in the phylogenetic analyses is provided in Table 1 . The entire length of the ITS1-5.8S-ITS2 region was $569 \mathrm{bp}$ for P. caspica; ITS1, 5.8 S and ITS2 length were 193, 163 and $214 \mathrm{bp}$, respectively. The 5.8S gene was not heterogeneous in size (156 bp). Conversely, with flowering plants, the ITS2 region had more variable sites in comparison to the ITS 1 region; the trnH-psbA intergenic spacer ranged from 288 to $301 \mathrm{bp}$ for all the two Populus species. Among the
288 positions of $t r n H-p s b A$, there were 17 parsimony positions for $P$. caspica, whereas only three sites were observed for NCBI under the study species. The trnL$F$ fragments and sequencing analysis revealed that $t r n L-$ $F$ of $P$. caspica and $P$. alba was 315 bp long; $28 \%$ of total nucleotides among all samples were $\mathrm{T}(\mathrm{U}), 15.4 \%$ were $\mathrm{C}$, $38.9 \% \mathrm{~A}$ and $15.4 \mathrm{G}$ (Table 1).

\section{Phylogenetic and network analysis}

The topology-based MP analyses of all three (ITS, trnH$p s b A, \operatorname{trn} L-F)$ regions are presented in Figs. 1 and 2. Based on the ITS analysis, the Populus species is divided into four clades. $P$. caspica taxa comprised three distinct clades with SC2, SA1 and $P$. alba (JQ898650) located in subclade 5 of clade 2 (Fig. 1), while that of $P$. alba, $P$. tremula $\times P$. alba, $P$. davidiana and $P$. hopeiensis are also in this clade. Based on the phylogenetic reconstruction of the two cpDNA regions, $P$. caspica formed a separate clade from the other Populus samples, except for SA1 taxa in trnH$p s b A$, which were located in subclade 5 of clade 1 (Fig. 2). Additionally, phylogenetic analysis of the cpDNA regions showed differences between $P$. caspica native to the Hyrcanian region and $P$. alba collected in Canada.

The minimum and maximum pairwise genetic distance, known as the Kimura-2-parameter distance (Kimura 1980), based on ITS sequence data from all taxa in this study in comparison to NCBI GenBank taxa, was assessed (Table 2). The results showed that all the Hyrcanian taxa (SA1, NY3, G2, N1 and SC1) were at a maximum distance from P. euphratica (JQ898635) species. However, the distance of these taxa from $P$. alba (JQ898650) varied from zero (SA1, SC2) to $0.005,0.007$ and 0.065 for N1, G2 and NY3, respectively. Additionally, Hyrcanian taxa showed a maximum distance with $P$. deltoides (AY757053) based on

Table 1 Characteristics of the ITS and trnH-psbA sequences

\begin{tabular}{|c|c|c|c|c|c|c|c|c|c|c|}
\hline \multirow[t]{3}{*}{ cpDNA or ITS regions } & \multicolumn{5}{|c|}{ Populus caspica } & \multicolumn{5}{|c|}{ Genbank Populus and Hamzeh's data* } \\
\hline & \multirow[t]{2}{*}{$\operatorname{trn} \mathrm{L}-F$} & \multirow[t]{2}{*}{$\operatorname{trn} \mathrm{H}-p s b \mathrm{~A}$} & \multicolumn{3}{|l|}{ ITS } & \multirow[t]{2}{*}{$\operatorname{trn} \mathrm{L}-F$} & \multirow[t]{2}{*}{$\operatorname{trn} \mathrm{H}-p s b \mathrm{~A}$} & \multicolumn{3}{|l|}{ ITS } \\
\hline & & & ITS1 & $5.8 \mathrm{~S}$ & ITS2 & & & ITS1 & $5.8 \mathrm{~S}$ & ITS2 \\
\hline $\mathrm{A}(\%)$ & 38.9 & 37.6 & 15.8 & 22.7 & 12.7 & 38.9 & 37.2 & 15.6 & 22.7 & 12.1 \\
\hline $\mathrm{C}(\%)$ & 15.4 & 13.2 & 34 & 26.9 & 36.6 & 30.3 & 17.6 & 34.8 & 26.7 & 38.1 \\
\hline $\mathrm{G}(\%)$ & 17.7 & 12.2 & 35.1 & 28.8 & 32.6 & 14 & 11.5 & 35.1 & 28.8 & 32.2 \\
\hline $\mathrm{T}(\mathrm{U} ; \%)$ & 28.0 & 34.3 & 15.1 & 21.6 & 18.2 & 16.9 & 33.7 & 14.5 & 21.7 & 17.6 \\
\hline Length (bp) & 315 & 288 & 192 & 163 & 214 & 335 & $288-301$ & 193-195 & 163 & 212 \\
\hline Conservation site & 303 & 207 & 188 & 163 & 183 & 296 & 284 & 180 & 162 & 194 \\
\hline Variable site & 10 & 80 & 4 & 0 & 30 & 13 & 10 & 12 & 0 & 18 \\
\hline Parsimony site & 1 & 17 & 3 & 0 & 1 & 7 & 3 & 8 & 0 & 10 \\
\hline
\end{tabular}

*Dr. Mona Hamzeh (Department of Biology, Concordia University, Canada) 
Fig. 1 Taxonomic position of $P$. caspica within the genus Populus based on the analysis of the nuclear DNA sequences (ITS-5.8S-ITS2) from this study with selected species from the NCBI gene bank: Maximum parsimony consensus original tree (> 50\%); Bootstrap 500; Salix sp. as an outgroup. Asterisk indicates samples from the Hyrcanian region

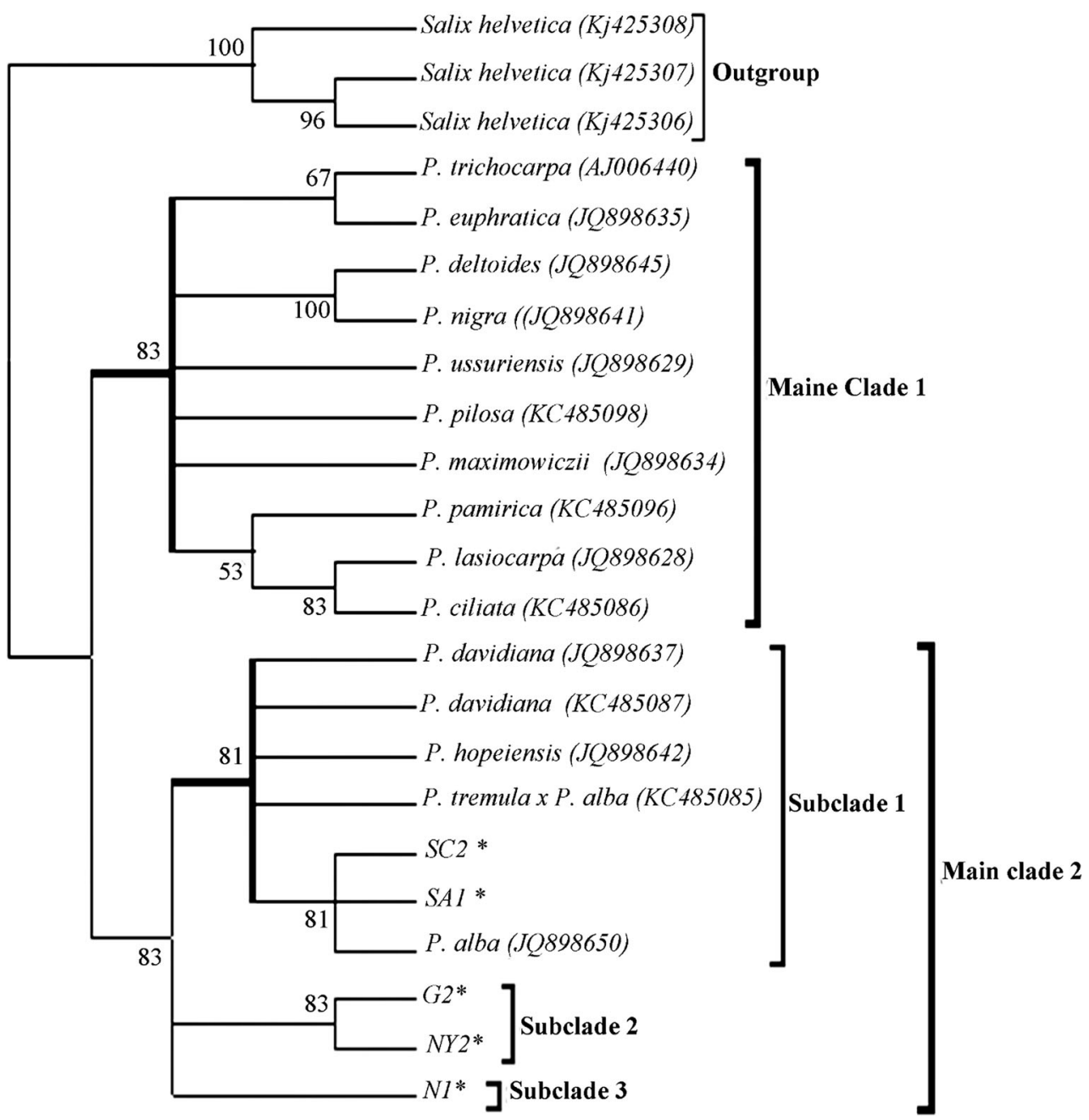

cpDNA and were differentiated from $P$. alba with a distance of 0.046, except for SA1 at 0.047 (Table 3).

According to the network analysis of cpDNA ( $\operatorname{trnH}$ $p s b A$ and $\operatorname{trn} L-F$ ), all Hyrcanian taxa originated from $P$. deltoides as haplogroup 1, except one taxa that originated from P. alba, as haplogroup 2 (Fig. 3a). Additionally, two ribotypes were identified according to the ITS analysis, which originated from $P$. tremula $\times P$. alba. These samples are N1, G2, and NY3 (ribotype 1) and SC2, SA1 (ribotype 2), as shown in Fig. 3b. Amplification of the entire ITS yielded two bands of approximately 700 and $500 \mathrm{bp}$ in some samples of $P$. caspica.

\section{Discussion}

Despite recent advances in the biology of Populus species, the relationships between species and taxonomic status of purported hybrids have remained controversial. For example, Gong (2004) classified P. pseudoglauca in the section Tacamahaca, while Ding and Fang (1993) proposed that this species belongs to the section Leucoides (Wan et al. 2013). Traditional classification studies are based only on the morphological characteristics without genetic identification, although morphological characteristics are easily influenced by environmental conditions. It is very difficult to precisely identify some species or varieties of Populus based strictly on morphology, particularly for similar species (Wan et al. 2013). The present study using chloroplast and nuclear nucleotide sequences to assess genetic differentiation between $P$. caspica, which is native to the Hyrcanian forest, and $P$. alba, revealed (1) significant topological incongruence, (2) significantly different data partitions between the cpDNA regions, (3) geographical differentiation among $P$. caspica populations, and (4) two variants of ITS in some $P$. caspica individuals.

This study showed that $P$. caspica sequences are different from those of $P$. alba (from studies by Hamzeh and Dayanandan 2004 and from NCBI GenBank). However, our results also showed that the sequences vary among the $P$. caspica populations. Sytsma and Schaal (1985) 


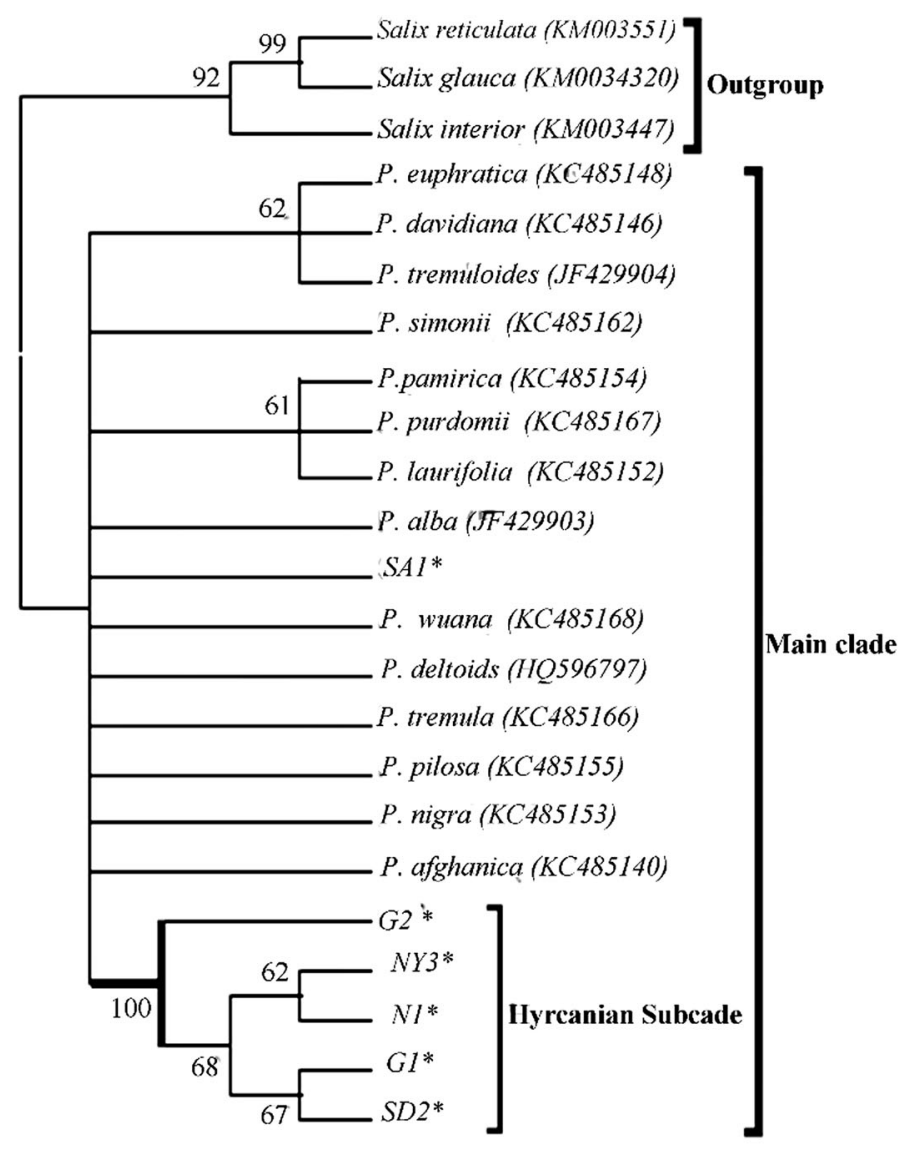

(a)

Fig. 2 Taxonomic position of P. caspica within the genus Populus based on the cpDNA analysis: a trnH-psbA, b trnL-F. Maximum parsimony consensus original tree $(>50 \%)$, Bootstrap 500; Asterisk

attributed variation in rDNA to genetic drift arising from spatial and genetic isolation between populations.

In recent years, many $P$. caspica habitats have been destroyed due to urbanization and changes in land use. Habitat fragmentation reduced extensive gene flow among populations and caused high genetic differentiation. Geographical differentiation of variants was observed within a population of Clematis fremontii, indicating population subdivisions consistent with limited gene flow within the population (Learn and Schaal 1987). Differentiation of rDNA among populations of both Picea rubens and $P$. mariana was attributed to genetic drift or forces related to ecogeographical selection (Bobola et al. 1992). Directional selection was responsible for substantial change in allelic frequencies in a population of barley over 53 generations (Saghai-Maroof et al. 1984). Genetic differentiation between populations was also observed in Phlox because of limited gene flow between populations (Schaal et al. 1987).

In this study, we observed conflicts between ITS and plastid topologies. The conflicts between topologies from different genomes can be explained by lineage sorting or

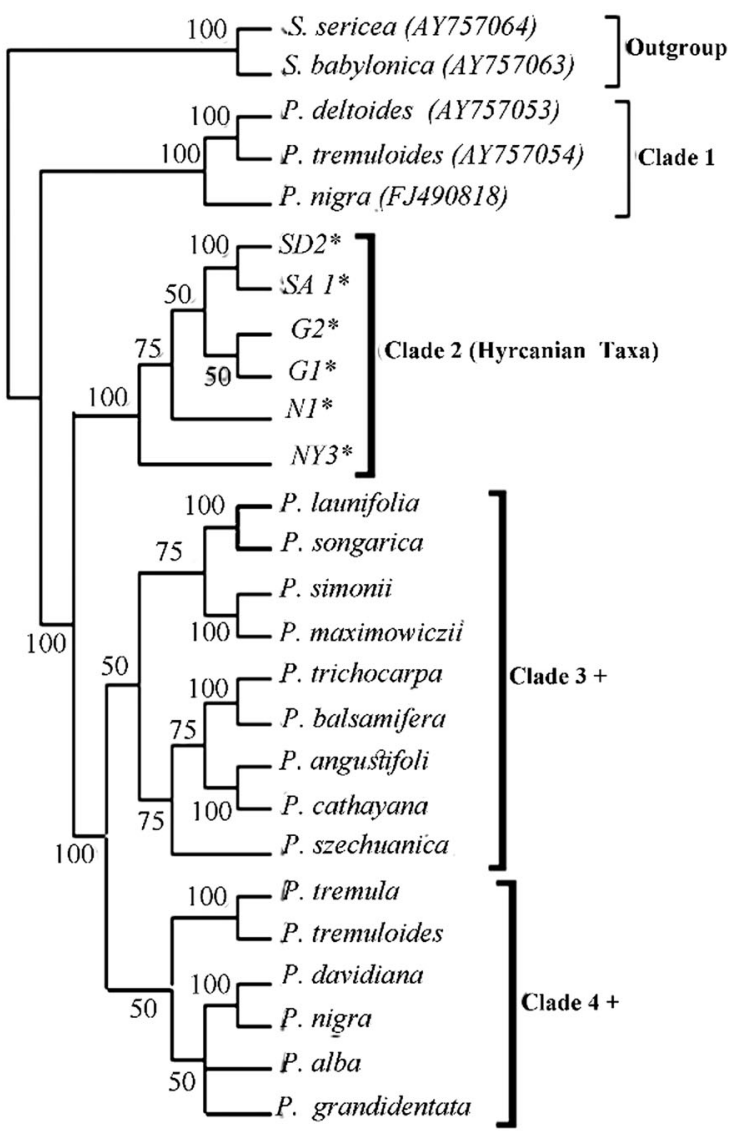

(b)

and plus symbols indicate the Hyrcanian samples and taxa obtained from Dr. Mona Hamzeh (Department of Biology, Concordia University, Canada), respectively

reticulation (Wendel and Doyle 1998), existence of past hybridization events and ITS paralogy (Catalan et al. 2004).

The conflicts between ITS and cpDNA topologies might be explained as convergent evolution, lineage sorting, or reticulate evolution (Raamsdonk et al. 1997; Degnan and Rosenberg 2009; Pelser et al. 2010; Feng et al. 2013; Leskinen and Alström-Rapaport 1999). In this work, a topological incongruence was noted for the two cpDNA regions, with displacement of the SA1. For the ITS data, SA1 and SC2 clustered with $P$. alba, but the other three samples were grouped in a separate clade (Clade 2). Different positions of SA1 on the cpDNA phylogenies indicate that cpDNA heterologous recombination occurred from more or less ancient hybridization, which has also been reported for the cpDNA genome of Picea (Bouille et al. 2011) and lodgepole pine (Marshall et al. 2001). However, the nrITS phylogenies support the recent hybridization between two species.

Additionally, within some individuals of $P$. caspica, two variants of ITS were observed. Similar patterns of multiple 
Table 2 Minimum and maximum pairwise genetic distance (Kimura-2-parameters distance) among analyzed Populus species based on the nuclear (ITS-5.8S-ITS2) DNA

\begin{tabular}{|c|c|c|c|c|c|c|c|c|c|c|}
\hline & N1 & $\mathrm{SC} 2$ & SA1 & $\mathrm{G} 2$ & NY3 & $6^{*}$ & $7 *$ & $8^{*}$ & $9 *$ & $10^{*}$ \\
\hline N1 & 0.000 & & & & & & & & & \\
\hline $\mathrm{SC} 2$ & 0.065 & 0.000 & & & & & & & & \\
\hline SA1 & 0.065 & 0.000 & 0.000 & & & & & & & \\
\hline G2 & 0.061 & 0.007 & 0.007 & 0.000 & & & & & & \\
\hline NY3 & 0.059 & 0.005 & 0.005 & 0.002 & 0.000 & & & & & \\
\hline P. tremula (KC485085) & 0.063 & 0.002 & 0.002 & 0.005 & 0.004 & 0.000 & & & & \\
\hline P. trichocarpa (AJ006440) & 0.087 & 0.028 & 0.028 & 0.029 & 0.028 & 0.026 & 0.000 & & & \\
\hline P. alba (JQ898650) & 0.065 & 0.000 & 0.000 & 0.007 & 0.005 & 0.002 & 0.028 & 0.000 & & \\
\hline P. deltoids (JQ898645) & 0.085 & 0.026 & 0.026 & 0.028 & 0.026 & 0.024 & 0.013 & 0.026 & 0.000 & \\
\hline P. hopeiensis (JQ898642) & 0.063 & 0.002 & 0.002 & 0.005 & 0.004 & 0.000 & 0.026 & 0.002 & 0.024 & 0.000 \\
\hline P. nigra (JQ898641) & 0.085 & 0.026 & 0.026 & 0.028 & 0.026 & 0.024 & 0.013 & 0.026 & 0.000 & 0.024 \\
\hline P. davidiana (JQ898637) & 0.063 & 0.002 & 0.002 & 0.005 & 0.004 & 0.000 & 0.026 & 0.002 & 0.024 & 0.000 \\
\hline P. euphratica (JQ898635) & 0.103 & 0.041 & 0.041 & 0.043 & 0.041 & 0.039 & 0.020 & 0.041 & 0.029 & 0.039 \\
\hline P. maximowiczii (JQ898634) & 0.078 & 0.020 & 0.020 & 0.022 & 0.020 & 0.018 & 0.009 & 0.020 & 0.013 & 0.018 \\
\hline P. ussuriensis (JQ898629) & 0.078 & 0.020 & 0.020 & 0.022 & 0.020 & 0.018 & 0.009 & 0.020 & 0.013 & 0.018 \\
\hline P. lasiocarpa (JQ898628) & 0.080 & 0.022 & 0.022 & 0.024 & 0.022 & 0.020 & 0.018 & 0.022 & 0.016 & 0.020 \\
\hline P. pilosa (KC485098) & 0.078 & 0.020 & 0.020 & 0.022 & 0.020 & 0.018 & 0.009 & 0.020 & 0.013 & 0.018 \\
\hline P. pamirica (KC485096) & 0.080 & 0.022 & 0.022 & 0.024 & 0.022 & 0.020 & 0.014 & 0.022 & 0.016 & 0.020 \\
\hline P. davidiana (KC485087) & 0.063 & 0.002 & 0.002 & 0.005 & 0.004 & 0.000 & 0.026 & 0.002 & 0.024 & 0.000 \\
\hline \multirow[t]{2}{*}{ P. ciliata_voucher (KC485086) } & 0.078 & 0.020 & 0.020 & 0.022 & 0.020 & 0.018 & 0.016 & 0.020 & 0.014 & 0.018 \\
\hline & $11 *$ & $12 *$ & $13 *$ & $14 *$ & & & & $17 *$ & $18 *$ & $19 *$ \\
\hline
\end{tabular}

N1

$\mathrm{SC} 2$

SA1

G2

NY3

P. tremula (KC485085)

P. trichocarpa (AJ006440)

P. alba (JQ898650)

P. deltoids (JQ898645)

P. hopeiensis (JQ898642)

P. nigra (JQ898641) 0.000

P. davidiana (JQ898637) $\quad 0.024$

P. euphratica (JQ898635) $\quad 0.029$

P. maximowiczii (JQ898634) 0.013

P. ussuriensis (JQ898629) 0.013

0.016

0.000

P. lasiocarpa (JQ898628)

0.013

0.039

$0.018 \quad 0.026$

P. pilosa (KC485098)

0.018

0.026

0.000

P. pamirica (KC485096)

0.016

0.020

0.000

0. 000

P. davidiana (KC485087)

0.024

0.018

0.009

0.009

0.000

P. ciliata_voucher (KC485086)

0.014

0.020

0.026

0.000

0.000

0.009

0.000

0.000

0.028
0.039

0.005

0.005

0.007

0.005

0.000

0.018

0.029

0.018

0.018

0.020

0.018

0.020

0.000

*6: P. tremula (KC485085); 7: P. trichocarpa (AJ006440); 8: P. alba (JQ898650): 9: P. deltoids (JQ898645); 10: P. hopeiensis (JQ898642); 11: P. nigra (JQ898641); 12: P. davidiana (JQ898637); 13: P. euphratica (JQ898635); 14: P. maximowiczii (JQ898634); 15: P. ussuriensis (JQ898629); 16: P. lasiocarpa (JQ898628); 17: P. pilosa (KC485098); 18: P. pamirica (KC485096); 19: P. davidiana (KC485087); 20: P 
Table 3 Minimum and maximum pairwise genetic distance (Kimura-2-parameters distance) among analyzed Populus species based on cpDNA*

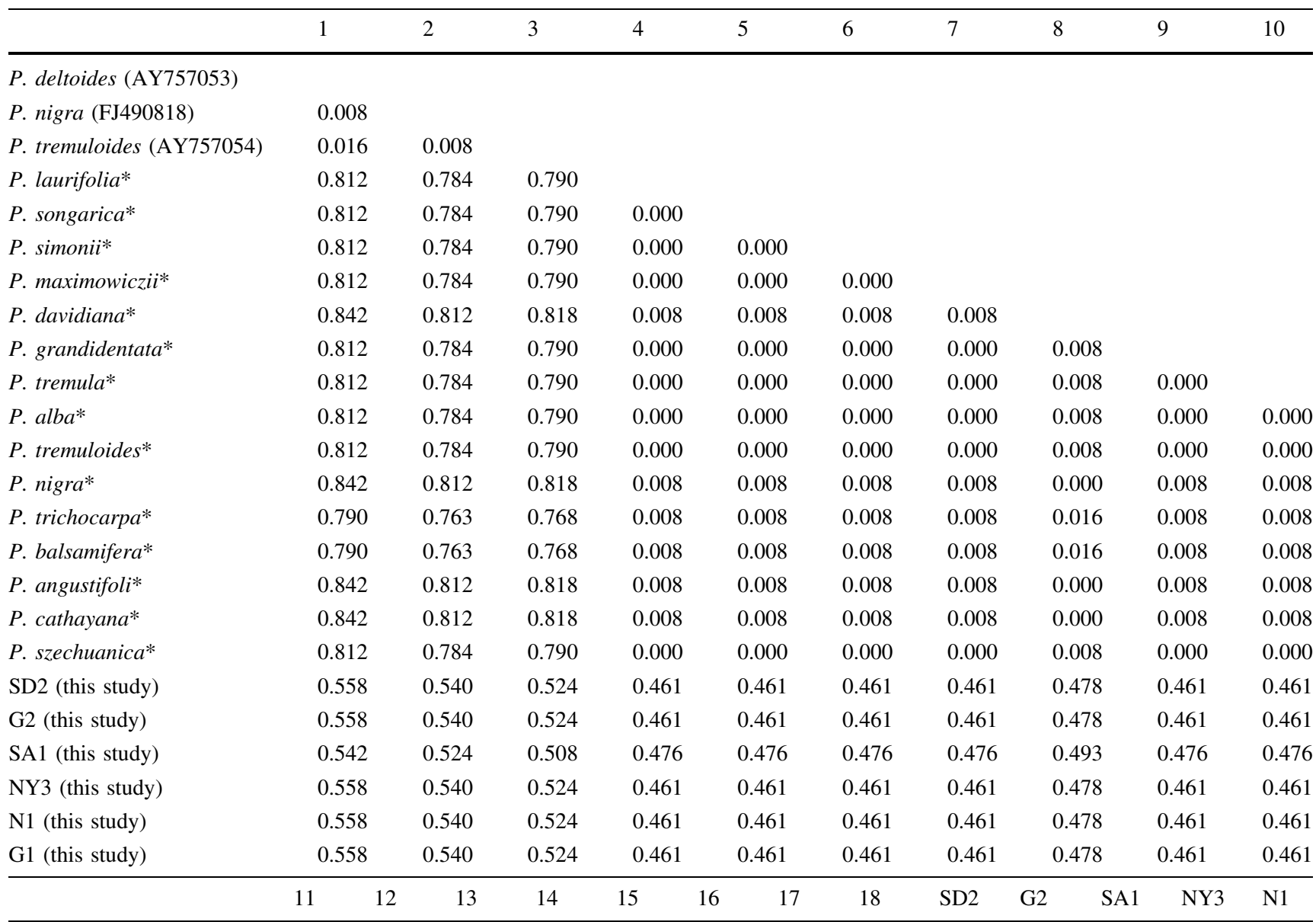

P. deltoides (AY757053)

P. nigra (FJ490818)

P. tremuloides (AY757054)

P. laurifolia*

P. songarica*

P. simonii*

P. maximowiczii*

P. davidiana*

P. grandidentata*

P. tremula*

P. alba*

P. tremuloides*

P. nigra*

P. trichocarpa*

P. balsamifera*

P. angustifoli*

P. cathayana*

P. szechuanica*

SD2 (this study)

G2 (this study)

SA1 (this study)

NY3 (this study)

0.000

$0.008 \quad 0.008$

$\begin{array}{lll}0.008 & 0.008 & 0.016\end{array}$

$\begin{array}{llll}0.008 & 0.008 & 0.016 & 0.000\end{array}$

$\begin{array}{lllll}0.008 & 0.008 & 0.000 & 0.016 & 0.016\end{array}$

$\begin{array}{llllll}0.008 & 0.008 & 0.000 & 0.016 & 0.016 & 0.000\end{array}$

$\begin{array}{llllllll}0.000 & 0.000 & 0.008 & 0.008 & 0.008 & 0.008 & 0.008\end{array}$

$\begin{array}{llllllll}0.461 & 0.461 & 0.478 & 0.476 & 0.476 & 0.478 & 0.478 & 0.461\end{array}$

$\begin{array}{llllllllll}0.461 & 0.461 & 0.478 & 0.476 & 0.476 & 0.478 & 0.478 & 0.461 & 0.000\end{array}$

$\begin{array}{llllllllll}0.476 & 0.476 & 0.493 & 0.491 & 0.491 & 0.493 & 0.493 & 0.476 & 0.008 & 0.008\end{array}$

$\begin{array}{llllllllllll}0.461 & 0.461 & 0.478 & 0.476 & 0.476 & 0.478 & 0.478 & 0.461 & 0.000 & 0.000 & 0.008\end{array}$ 
Table 3 continued

\begin{tabular}{llllllllllllll}
\hline & 11 & 12 & 13 & 14 & 15 & 16 & 17 & 18 & SD2 & G2 & SA1 & NY3 & N1 \\
\hline N1 (this study) & 0.461 & 0.461 & 0.478 & 0.476 & 0.476 & 0.478 & 0.478 & 0.461 & 0.000 & 0.000 & 0.008 & 0.000 \\
G1 (this study) & 0.461 & 0.461 & 0.478 & 0.476 & 0.476 & 0.478 & 0.478 & 0.461 & 0.000 & 0.000 & 0.008 & 0.000 & 0.000
\end{tabular}

*trnL-F sequences of these taxa obtained from Dr. Mona Hamzeh (Department of Biology, Concordia University, Canada); $1: P$. deltoides (AY757053); 2: P. nigra (FJ490818); 3: P. tremuloides (AY757054); 4; P. laurifolia; 5: P. songarica; 6: P. simonii; 7: P. maximowiczii; 8: P. davidiana: 9: P. grandidentata; 10: P. tremula; 11: P. alba; 12: P. tremuloides; 13; P. nigra; 14: P. trichocarpa; 15: P. balsamifera; 16: P. angustifoli; 17: P. cathayana; 18: P. szechuanica

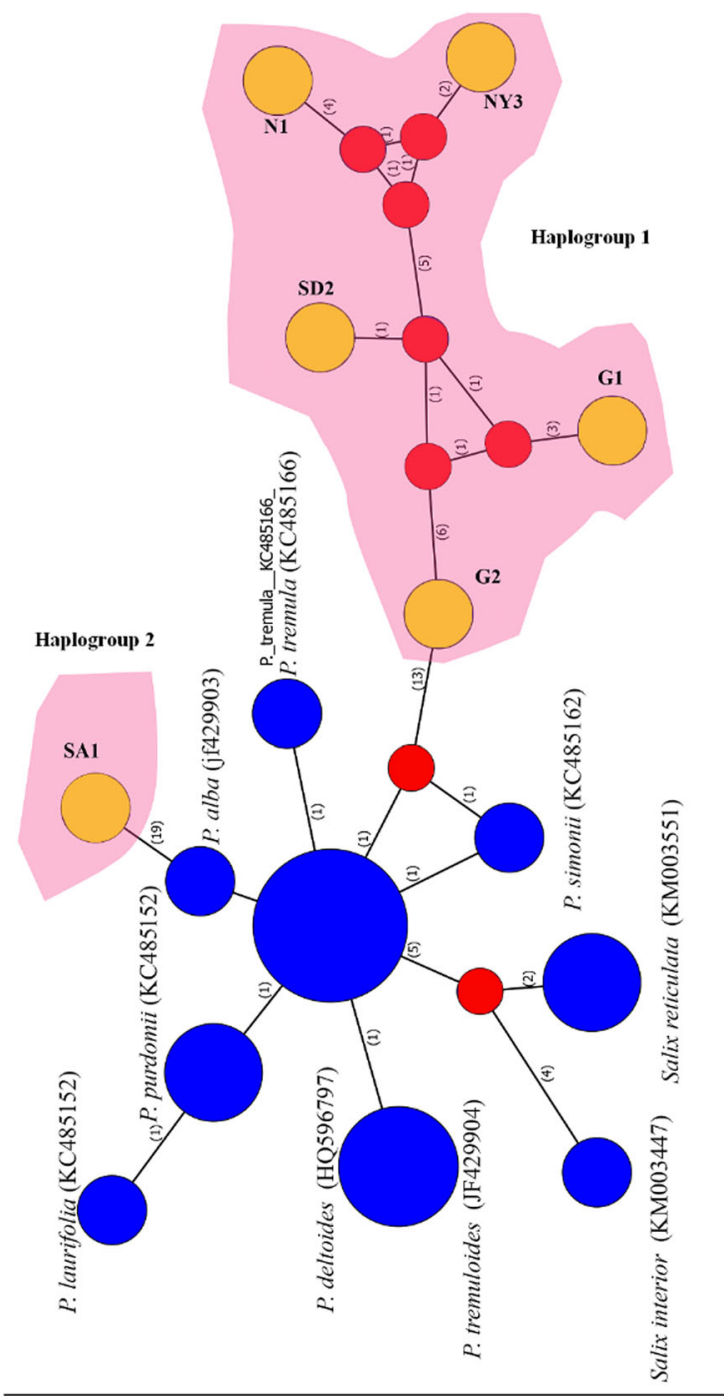

(a) cpDNA (trnH-psbA \& trnL-F)

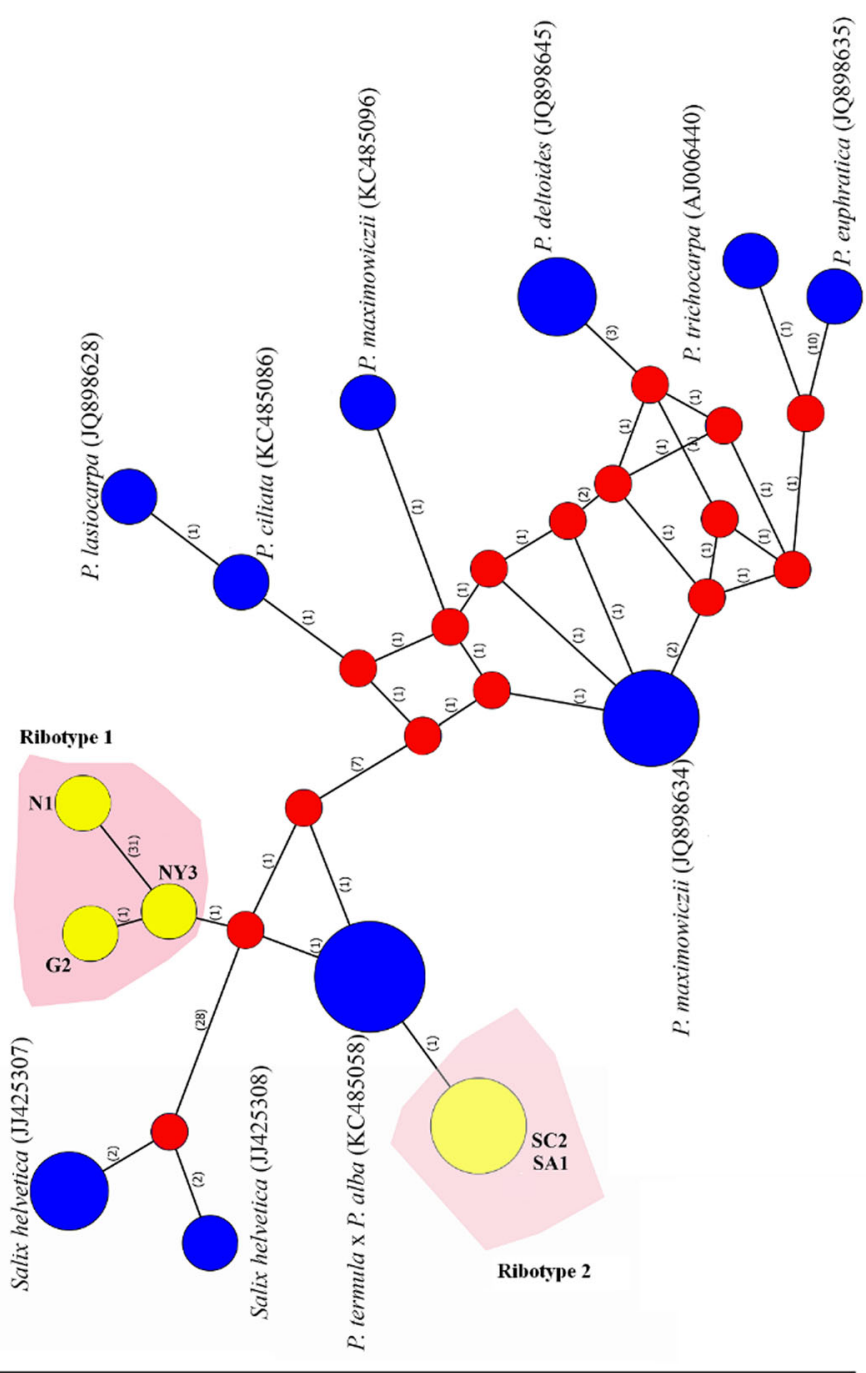

(b) Nuclear DNA (ITS-5.8S-ITS2)
Fig. 3 Phylogenetic network combining chloroplast and nuclear DNA data within the genus Populus: a cpDNA (trnH-psbA and trnL-F), b nuclear DNA (ITS-5.8S-ITS2); Blue, red and yellow

rDNA length variants within individuals have been observed in other long-lived outbreeding species, such as wind-pollinated oaks (Bellarosa et al. 1990) and insectpollinated rubber trees (Besse et al. 1993). circles are proportional to the number of species belonging to the same SNP, median vector and the Hyrcanian samples, respectively

Differences in life history traits, breeding systems and the level of gene flow are the main determinant factors of extensive outcrossing of individuals within and between populations. Therefore, the level of gene flow in this 
species with a foreign species is sufficient to prevent both the homogenization of rDNA variants within individuals and the divergence of rDNA between populations (Mclain et al. 1995; Keller et al. 2008).

Numerous examples of natural or spontaneous hybridization in Populus have been documented or proposed (Barnes and Pregitzer 1985; Smith and Sytsma 1990). Extensive planting of exotic poplars, such as $P . \times$ euramericana and P. termuloides, in the Hyrcanian forest increase a risk of hybridization and introgression. The possibility of hybridization between $P$. alba and $P$. tremuloides and between $P$. alba and $P$. tremula are confirmed and are called Populus $\times$ heimburgeri Bovin and Populus $\times$ canescens, respectively. In this case, gene exchange (hybridization and introgression) between $P$. caspica and exotic species considered as genetic pollutants is of great concern for forest trees because they can have large effects on ecosystem processes and biological diversity (Nishimoto et al. 2003; DiFazio et al. 2004). Poplar plantations with foreign species, such as $P$. euroamericana, are a threat to the diversity and regeneration of native indigenous poplars. For example, in Europe, the European black poplar is threatened by the euramerican $P . \times$ canadensis Moench. and interamerican $P . \times$ generosa Henry hybrids as well as by $P$. nigra varieties, such as the male Lombardy poplar, Populus nigra cv. Italica Duroi (Heinze 1998; Lefèvre et al. 2001). Habitat fragmentation, human activities for reduction of plains area and widespread cultivation of exotic species are three main reasons for $P$. caspica being on the verge of extinction. Therefore, $P$. caspica is the only poplar forest species in the Hyrcanian forest faced with a large threat due to agriculture and urbanization of floodplain areas and hybridization with cultivated poplar that threaten the survival of the species.

\section{Conclusions}

Populus caspica is an indicator and endemic tree species growing in Hyrcanian forests together with Parrotia persica, Ulmus carpinifolia, Alnus glutinosa, Quercus castaneifolia, Pterocarya fraxinifolia, and others. Habitat fragmentation, human activities for the reduction of the plains area and widespread cultivation of exotic species are three main reasons for $P$. caspica being on the verge extinction. High differentiation of $P$. caspica from the other Populus species confirmed the special taxonomic status of this species in the genus. This study has also demonstrated the presence of hybrids between cultivated Populus with $P$. caspica in the Hyrcanian forest. Additionally, our study showed the presence of two ITS copies in some individuals, consistent with observations of spontaneous hybridization among these species in nature and in cultivation (Hamzeh and Dayanandan 2004). For example, hybrid $P . \times$ euramericana is a spontaneous hybrid between European P. nigra and North American $P$. deltoides (Lefèvre et al. 2001; Hamzeh et al. 2006).

Hybridization could occur between $P$. caspica and $P$. deltoides and or $P . \times$ euramericana because these tree species are cultivated in the Hyrcanian region. Thus, interand intra-sectional hybridization between $P$. caspica with other species is a major cause of the disagreement on the total number of poplar species and their classification.

However, due to strong disturbance and fragmentation, conservation of large parts of natural distribution areas of $P$. caspica might not be possible, so protection of selected stands of this species is highly recommended (in situ conservation) to provide stock material for further breeding and maintaining a large gene pool that will evolve over time in response to environmental changes. Further studies on intra-genomic rDNA variation in Populus species might shed more light on the fundamental mechanisms of concerted evolution and speciation and also environmental rDNA sequence data in plants.

This study is the first report on the phylogenetic relationship of P. caspica with other Populus species. However, using morphological data and other molecular markers, such as genus-specific microsatellite markers, and sharing voucher specimens with other Populus genetic researchers could be useful for more accurate conclusions.

Acknowledgements We are tremendously grateful to Dr. Mona Hamzeh, Department of Biology, Concordia University, for providing of some Canadian samples sequences. Also, we thank Fatemeh Mostajeran and Hamid Bina, Tarbiat Modares University, Noor, Mazandaran, Iran, for help with data collections.

\section{References}

Akbarzadeh Roshan F, Colagar AH, Yosefzadeh H (2013) Taxonomic status and genetic variation of the genus Castanea (Fagaceae) in Iran based on $p s b A$ and trnH-psbA. Rostaniha 14(2):229-237

Akhani H, Djamali M, Ghorbanalizadeh A, Ramezani E (2010) Plant biodiversity of Hyrcanian relict forests, $\mathrm{N}$ Iran: an overview of the flora, vegetation, paleoecology and conservation. Pak J Bot 42:231-258

Barnes BV, Pregitzer KS (1985) Occurrence of hybrids between big tooth and trembling aspen in Michigan. Can J Bot 63(10):1888-1890

Bellarosa R, Delre V, Schirone B, Maggini F (1990) Ribosomal RNA genes in Quercus spp. (Fagaceae). Plant Syst Evol 172:127-139

Besse P, Seguin M, Lebrun P, Lanaud C (1993) Ribosomal DNA variations in wild and cultivated rubber tree (Hevea brasiliensis). Genome 36(6):1049-1057

Bobola MS, Eckert RT, Klein AS (1992) Restriction fragment variation in the nuclear ribosomal DNA repeat unit within and between Picea rubens and Picea mariana. Can J For Res 22(2):255-263 
Bouillé M, Senneville S, Bousquet J (2011) Discordant mtDNA and cpDNA phylogenies indicate geographic speciation and reticulation as driving factors for the diversification of the genus Picea. Tree Genet Genom 7(3):469-484

Brinegar C (2009) Assessing evolution and biodiversity in plants at the molecular level. Kathmandú Univ J Sci Eng Technol 5(2):149-159

Catalan P, Torrecilla P, Rodriguez JAL, Olmstead RG (2004) Phylogeny of the festucoid grasses of subtribe Loliinae and allies (Poeae, Pooideae) inferred from ITS and $t r n L-F$ sequences. Mol Phylogenet Evol 31(2):517-541

Cervera MT, Cervera VMT, Sewell MM, Faivre-Rampant P, Storme S, Van Montagu M, Boerjan W (2004) Genome mapping in Populus. In: Kumar S, Fladung M (eds) Molecular genetics and breeding of forest trees. Haworth's Food Products, New York, pp 387-410

Colagar AH, Saadati M, Zarea M, Talei SA (2010) Genetic variation of the Iranian Sclerotinia sclerotiorum isolates by standardizing DNA polymorphic fragments. Biotechnol 9(1):67-72

Colagar AH, Yusefi M, Zarei M, Yousefzadeh H (2013) Assessment of genetic diversity of Tilia rubra DC. by RAPD analysis in the Hyrcanian forests, north of Iran. Pol J Ecol 61(2):341-348

Degnan JH, Rosenberg NA (2009) Gene tree discordance, phylogenetic inference and the multispecies coalescent. Trends Ecol Evol 24(6):332-340

Dickmann DI, Isebrands JG, Eckenwalder JE, Richardson J (2001) Poplar culture in North America. NRC research, National Research Council of Canada, Ottawa, Ontario, Canada

DiFazio SP, Slavov GT, Burczyk J, Leonardi S, Strauss SH (2004) Gene flow from tree plantations and implications for transgenic risk assessment. In: Walter C, Carson M (eds) Plantation forest biotechnology for the 21st Century. Research Signpost, Thiruvananthapuram, pp 405-422

Ding TY, Fang CF (1993) New taxa of Salix L. from west China. Acta Phytotaxon Sin 31(3):277-280 (in Chinese with English abstract)

Fallah H, Jalali SGA, Tabari M, Chapolagh Paridari I (2012) Indicator plant species and site conditions of Persian Poplar populations in Hyrcanian Forest (Iran). Ann Biol Res 3(6):2763-2770

Feng J, Jiang D, Shang H, Dong M, Wang G, He X, Zhao C, Mao K (2013) Barcoding poplars (Populus L.) from western China. PLoS ONE 8(8):e71710

Fukuda S, Toh H, Hase K, Oshima K, Nakanishi Y, Yoshimura K, Tobe T, Clarke JM, Topping DL, Suzuki T, Taylor TD, Itoh K, Kikuchi J, Morita H, Hattori M, Ohno H (2011) Bifidobacteria can protect from enteropathogenic infection through production of acetate. Nature 469:543

Gong GT (2004) The geographic distribution and origin of Populus L. J Sichuan For Sci Technol 25(2):25-30 (in Chinese with English abstract)

Green MR, Sambrook J (2012) Molecular cloning: a laboratory manual. Cold Spring Harbor Laboratory Press, Cold Spring Harbor

Hamzeh M, Dayanandan S (2004) Phylogeny of Populus (Salicaceae) based on nucleotide sequences of chloroplast TRNT-TRNF region and nuclear rDNA. Am J Bot 91(9):1398-1408

Hamzeh M, Perinet P, Dayanandan S (2006) Genetic relationships among species of Populus (Salicaceae) based on nuclear genomic data. J Torrey Bot Soc 133(4):519-527

Heinze B (1998) PCR-Based chloroplast DNA assays for the identification of native Populus nigra and introduced poplar hybrids in Europe. For Genet 5(1):31-38

Holt SD, Horova L, Bures P (2004) Indel patterns of the plastid DNA trnL-trnF region within the genus Poa (Poaceae). J Plant Res 117:393-407
Keller I, Veltsos P, Nichols RA (2008) The frequency of rDNA variants within individuals provides evidence of population history and gene flow across a grasshopper hybrid zone. Evolution 62(4):833-844

Khasa DP, Nadeem S, Thomas B, Robertson A, Bousquet J (2003) Application of SSR markers for parentage analysis of populus clones. For Genet 10(4):273-282

Kimura M (1980) A simple method for estimating evolutionary rate of base substitutions through comparative studies of nucleotide sequences. J Mol Evol 16:111-120

Kojoma M, Kurihara K, Yamada K, Sekita S, Satake M, Iida O (2002) Genetic identification of cinnamon (Cinnamomum spp.) based on the trnL-trnF chloroplast DNA. Planta Med 68(1):94-96

Learn GH, Schaal BA (1987) Population subdivision for ribosomal DNA repeat variants in Clematis fremontii. Evolution 41:433-438

Leestmans R (2005) Le refuge caspiens et son importance en biogeographie. Linneana Belg 20(3):97-102

Lefèvre F, Kajba D, Heinze B, Rotach P, de Vries SM, Turok J (2001) Black poplar: a model for gene resource conservation in forest ecosystems. For Chron 77(2):239-244

Leigh JW, Bryant D (2014) PopART. Available at http://popart.otago. ac.nz. Accessed 28 Feb 20114

Leskinen E, Alström-Rapaport C (1999) Molecular phylogeny of Salicaceae and closely related Flacourtiaceae: evidence from 5.8S, ITS1 and ITS2 of the rDNA. Plant Syst Evol 215:209-227

Marshall HD, Newton C, Ritland K (2001) Sequence-repeat polymorphisms exhibit the signature of recombination in lodgepole pine chloroplast DNA. Mol Biol Evol 18(11):2136-2138

Mclain DK, Wesson DM, Oliver JH, Collins FH (1995) Variation in ribosomal DNA internal transcribed spacers 1 among eastern populations of Ixodes scapularis (Acari: Ixodidae). J Med Entomol 32(3):353-360

Nei M (1987) Molecular evolutionary genetics. Columbia University, New York, p 512

Nishimoto Y, Ohnishi O, Hasegawa M (2003) Topological incongruence between nuclear and chloroplast DNA trees suggesting hybridization in the urophyllum group of the genus Fagopyrum (Polygonaceae). Genes Genet Syst 78(2):139-153

Nitta JH, O'Grady PM (2008) Mitochondrial phylogeny of the endemic Hawaiian craneflies (Diptera, Limoniidae, Dicranomyia): implications for biogeography and species formation. Mol Phylogenet Evol 46(3):1182-1190

Pelser PB, Kennedy AH, Tepe EJ, Shidler JB, Nordenstam B, Kadereit JW, Watson LE (2010) Patterns and causes of incongruence between plastid and nuclear Senecioneae (Asteraceae) phylogenies. Am J Bot 97(5):856-873

Pirie MD, Vargas MPB, Botermans M, Bakker F, Chatrou LW (2007) Ancient paralogy in the cpDNA trnL-F region in annonaceae: implications for plant molecular systematic. Am J Bot 94(6): 1003-1016

Quandt D, Müller K, Stech M, Frahm JP, Frey W, Hilu KW, Borsch T (2004) Molecular evolution of the chloroplast $\operatorname{trn} L-F$ region in land plants. Monogr Sys Bot Missouri Bot Garden 98:13-37

Raamsdonk LWV, Smiech MP, Sandbrink JM (1997) Introgression explains incongruence between nuclear and chloroplast DNA based phylogenies in Allium section Cepa. Bot J Linnean Soc 123(2):91-108

Rechinger KH (1982) Flora Iranica: Akademische Druck-und Verlagsanstalt Graz. University of Tehran, Tehran, p 549

Saghai-Maroof MA, Soliman KM, Jorgensen RA, Allard RW (1984) Ribosomal DNA spacer-length polymorphisms in barley: mendelian inheritance, chromosomal location, and population dynamics. Proc Natl Acad Sci 81(24):8014-8018 
Schaal BA, Leverich WJ, Nieto-Sotelo J (1987) Ribosomal DNA variation in the native plant Phlox divaricata. Mol Biol Evol 4(6):611-621

Smith RL, Sytsma KJ (1990) Evolution of Populus nigra (sect. Aigeiros): introgressive hybridization and the chloroplast contribution of Populus alba (sect. Populus). Am J Bot 77(9):1176-1187

Sytsma KJ, Schaal BA (1985) Phylogenetics of the Lisianthius skinneri (Gentianaceae) species complex in Panama utilizing DNA restriction fragment analysis. Evolution 39(3):594-608

Taberlet P, Gielly L, Pautou G, Bouvet J (1991) Universal primers for amplification of three non-coding regions of chloroplast DNA. Plant Mol Biol 17:1105-1109

Tamura K, Stecher G, Peterson D, Filipski A, Kumar S (2013) Brief communication MEGA6: molecular evolutionary genetics analysis version 6.0. Mol Biol Evol 30(12):2725-2729

Tang L, Tang JM, Li Tan Si, Ju Ma X, Zhou ZQ (2015) ITS sequence variation and concerted evolution in the natural hybrid species Malus toringoides. Nordic J Bot 33:109-119

Tsai LC, Hsieh HM, Huang LH, Wang JC, Linacre A, Lee JCI (2006) Cannabis seed identification by chloroplast and nuclear DNA. Foren Sci Int 158(2):250-251

Tuskan GA, Difazio S, Jansson S, Bohlmann J, Grigoriev I, Hellsten U, Putnam N, Ralph S, Rombauts S, Salamov A, Schein J, Sterck L, Aerts A, Bhalerao RR, Bhalerao RP, Blaudez D, Boerjan W, Brun A, Brunner A, Busov V, Campbell M, Carlson J, Chalot M, Chapman J, Chen GL, Cooper D, Coutinho PM, Couturier J, Covert S, Cronk Q, Cunningham R, Davis J, Degroeve S, Déjardin A, Depamphilis C, Detter J, Dirks B, Dubchak I, Duplessis S, Ehlting J, Ellis B, Gendler K, Goodstein D, Gribskov M, Grimwood J, Groover A, Gunter L, Hamberger B, Heinze B, Helariutta Y, Henrissat B, Holligan D, Holt R, Huang
$\mathrm{W}$, Islam-Faridi $\mathrm{N}$, Jones $\mathrm{S}$, Jones-Rhoades $\mathrm{M}$, Jorgensen $\mathrm{R}$, Joshi C, Kangasjärvi J, Karlsson J, Kelleher C, Kirkpatrick R, Kirst M, Kohler A, Kalluri U, Larimer F, Leebens-Mack J, Leplé JC, Locascio P, Lou Y, Lucas S, Martin F, Montanini B, Napoli C, Nelson DR, Nelson C, Nieminen K, Nilsson O, Pereda V, Peter G, Philippe R, Pilate G, Poliakov A, Razumovskaya J, Richardson P, Rinaldi C, Ritland K, Rouzé P, Ryaboy D, Schmutz J, Schrader J, Segerman B, Shin H, Siddiqui A, Sterky F, Terry A, Tsai CJ, Uberbacher E, Unneberg P, Vahala J, Wall K, Wessler S, Yang G, Yin T, Douglas C, Marra M, Sandberg G, Van de Peer Y, Rokhsar D (2006) The genome of black cottonwood, Populus trichocarpa (Torr. \& Gray). Science 313(5793):1596-1604

Wan XQ, Zhang F, Zhong Y, Ding YH, Wang CL, Hu TX (2013) Study of genetic relationships and phylogeny of the native Populus in Southwest China based on nucleotide sequences of chloroplast trnT-trnF and nuclear DNA. Plant Syst Evol 299(1):57-65

Wendel JF, Doyle JJ (1998) Phylogenetic incongruence: window into genome history and molecular evolution. Mol Syst Plants II. Springer, US, pp 265-296

Yi T, Miller AJ, Wen J (2004) Phylogenetic and biogeographic diversification of Rhus (Anacardiaceae) in the Northern Hemisphere. Mol Phylogenet Evol 33(3):861-879

Yousefzadeh H, Colagar AH, Tabari M, Sattarian A, Assadi M (2012) Utility of ITS region sequence and structure for molecular identification of Tilia species from Hyrcanian forests, Iran. Plant Syst Evol 298(5):947-961

Yousefzadeh H, Colagar AH, Akbarzadeh Roshan F, Tippery NP (2014) Taxonomic status and genetic differentiation of Hyrcanian Castanea based on noncoding chloroplast DNA sequences data. Tree Genet Genom 10(6):1611-1629 